\title{
Parental risk factors for congenital diaphragmatic hernia - a large German case-control study
}

\author{
Felicitas Schulz ${ }^{1,2^{*}}$, Ekkehart Jenetzky ${ }^{3,4}$, Nadine Zwink $^{3}$, Charlotte Bendixen ${ }^{5}$, Florian Kipfmueller ${ }^{1}$, Neysan Rafat ${ }^{6}$, \\ Andreas Heydweiller ${ }^{7}$, Lucas Wessel ${ }^{8}$, Heiko Reutter ${ }^{1,9}$, Andreas Mueller $^{1}$ and Thomas Schaible ${ }^{6}$
}

\begin{abstract}
Background: Evidence for periconceptional or prenatal environmental risk factors for the development of congenital diaphragmatic hernia $(\mathrm{CDH})$ is still scarce. Here, in a case-control study we investigated potential environmental risk factors in $199 \mathrm{CDH}$ patients compared to 597 healthy control newborns.

Methods: The following data was collected: time of conception and birth, maternal BMI, parental risk factors such as smoking, alcohol or drug intake, use of hairspray, contact to animals and parental chronic diseases. CDH patients were born between 2001 and 2019, all healthy control newborns were born in 2011. Patients and control newborns were matched in the ratio of three to one.

Results: Presence of $\mathrm{CDH}$ was significantly associated with maternal periconceptional alcohol intake (odds ratio $=$ $1.639,95 \%$ confidence interval $1.101-2.440, p=0.015$ ) and maternal periconceptional use of hairspray (odds ratio $=$ $2.072,95 \%$ confidence interval 1.330-3.229, $p=0.001$ ).

Conclusion: Our study suggests an association between $\mathrm{CDH}$ and periconceptional maternal alcohol intake and periconceptional maternal use of hairspray. Besides the identification of novel and confirmation of previously described parental risk factors, our study underlines the multifactorial background of isolated CDH.
\end{abstract}

Keywords: Birth defect, $\mathrm{CDH}$, Congenital diaphragmatic hernia, Environmental risk factor

\section{Background}

Congenital diaphragmatic hernia $(\mathrm{CDH})$ represents a severe birth-defect with an estimated birth prevalence of 1 in 2500 newborns [1]. It is characterized by a defect in the embryonic development of the diaphragm which results in an incomplete separation of the abdominal cavity and the thoracic cavity. This incomplete separation leaves to variable degrees stomach, intestine, liver or spleen displaced in the thoracic cavity compromising

\footnotetext{
* Correspondence: felicitas.schulz@uni-bonn.de

'Department of Neonatology and Pediatric Intensive Care, Children's Hospital, University of Bonn, Bonn, Germany

${ }^{2}$ Department of Hematology, Oncology and Clinical Immunology, University Hospital Düsseldorf, Düsseldorf, Germany

Full list of author information is available at the end of the article
}

pulmonary development with concomitant pulmonary hypoplasia and secondary pulmonary hypertension at birth [2]. Normally, the diaphragm develops during the fourth week of gestation and closes until twelfth week [3]. Different types of $\mathrm{CDH}$ are classified according to their location. The most common type is the posterolateral Bochdalek hernia, a defect in the lumbocostal trigonum with herniation mostly resulting left-sided [4]. Current knowledge on the underlying cause for $\mathrm{CDH}$ is still scarce. Genetic factors might play an important role since about $20 \%$ occur as part of a genetic defect or syndrome [5]. In the majority of cases $\mathrm{CDH}$ presents as an isolated defect or as one of many malformations without any genetic abnormality detected [6]. The most common

(c) The Author(s). 2021 Open Access This article is licensed under a Creative Commons Attribution 4.0 International License, which permits use, sharing, adaptation, distribution and reproduction in any medium or format, as long as you give appropriate credit to the original author(s) and the source, provide a link to the Creative Commons licence, and indicate if changes were made. The images or other third party material in this article are included in the article's Creative Commons licence, unless indicated otherwise in a credit line to the material. If material is not included in the article's Creative Commons licence and your intended use is not permitted by statutory regulation or exceeds the permitted use, you will need to obtain permission directly from the copyright holder. To view a copy of this licence, visit http://creativecommons.org/licenses/by/4.0/. The Creative Commons Public Domain Dedication waiver (http://creativecommons.org/publicdomain/zero/1.0/) applies to the data made available in this article, unless otherwise stated in a credit line to the data. 
co-occuring malformations compromise the cardiovascular, genitourinary, gastrointestinal or the central nervous system [7]. Besides genetic factors the following environmental risk factors have been previously associated with the development of $\mathrm{CDH}$ : maternal body mass index (BMI) [8], maternal age [9, 10], pre-gestational diabetes [11], maternal pre-gestational hypertension [12], pre-conceptional diet, especially riboflavin supplementation [13].

In the present study, we hypothesized that periconceptional and prenatal environmental factors have a greater impact on the development of $\mathrm{CDH}$ than previously assumed [14]. Here we compared the impact of parental periconceptional smoking and alcohol intake, maternal periconceptional exposure to coffee, sweeteners and hairspray as well as maternal body mass index (BMI). Furthermore, we analyzed if the development of $\mathrm{CDH}$ might be influenced by chronic diseases like maternal hypothyroidism or maternal periconceptional folic acid intake, previous miscarriages or infertility treatment. We compared data of environmental risk factors obtained from $199 \mathrm{CDH}$ patients born at the University Hospital of Bonn and the University Hospital of Mannheim between 2001 and 2019 to data of environmental risk factors obtained from 597 healthy control newborns born all over Germany in 2011.

\section{Methods}

\section{Patients and families}

We designed a case-control study with regard to $\mathrm{CDH}$ patients born at the University Hospitals of Bonn and Mannheim. Both hospitals represent the largest centers in Germany for the treatment and care of $\mathrm{CDH}$ newborns. The respective ethics committees of the University Hospital of Bonn and Mannheim approved our study. Prior to inclusion, written informed consent was obtained from all patients respectively their parents. For our analysis we used data of $\mathrm{CDH}$ newborns born in Bonn between 2001 and 2019 and born in Mannheim between 2001 and 2016. We did not contact families retrospectively in whom we knew, that the index patient had passed away. Initially, we contacted $647 \mathrm{CDH}$ families. All families that consented to participate were recontacted via phone for further explanations about the study's design.

\section{Epidemiologic questionnaire}

The families received our study questionnaire from CURE-Net, which is an ongoing, multicenter, population-based study initiated in 2009. The same questionnaire has been previously used to investigate environmental risk factors for urorectal malformations [15].
This questionnaire comprises of 14 pages including a standardized case report form to document the phenotype, family history and the presence of any co-morbid disorders. In addition, it surveys demographic information from patients and their families in accordance to the EUROCAT (European surveillance of congenital anomalies) report forms (http://www.eurocat-network. $\mathrm{eu} /$ ). This information was amended for sociodemographic factors, the periconceptional and prenatal period, the child's birth and the parents' lifestyle regarding to nutrition or potential noxious agents.

\section{Study design}

In detail, the following classification of risk factors were made for our study: Parental smoking as well as parental alcohol, coffee or sweetener intake and the use of hairspray was recorded both for the periconceptional time and the rest of pregnancy. Periconceptional was defined as 3 months before conception until the end of the first trimester. Maternal BMI was calculated using the height and weight at the beginning and end of pregnancy. Because $\mathrm{CDH}$ formation occurs within the first trimester as mentioned above, we focused on the abovementioned time frame for our analysis. Maternal chronic diseases were recorded as free text questions. Folic acid intake was documented with regards to date of initiation and dosage of supplementation. Previous miscarriages were listed and a previous infertility treatment was specified into two subgroups of hormonal treatment exclusively or followed by in vitro fertilization (IVF)/intracytoplasmic sperm injection (ICSI). Parental contact to animals was recorded by listing the respective animals.

\section{Response and control group}

Of the 336 questionnaires sent out via mail, 201 were returned. We decided to exclude all $\mathrm{CDH}$ cases with chromosomal anomalies, suspected genetic syndromes or molecular diagnosis of a genetic syndrome. Associated malformations were recognized using the physician's letters of the respective hospitalization. Finally, we compared data of $199 \mathrm{CDH}$ cases born in Bonn and Mannheim between 2001 and 2019 with 597 infants without congenital malformations born in 2011. The control questionnaires were gathered just after births, the case questionnaires several years later. Since the $\mathrm{CDH}$ patients born in Bonn and Mannheim originally came from all over Germany to be delivered in these two centers, we used only healthy control newborns that were also collected from all over Germany. Their families received the same questionnaire directly after the child's birth. The control group was not gender matched. To increase the power, we chose a 3:1 match control:cases. Controls with an identical distribution regarding the year of birth were not available. 


\section{Statistical analysis}

Nonparametric measurement methods (chi square-test, Mann-Whitney-U test) were used to calculate possible differences between cases and controls. For potential parental risk factors we calculated the odds ratio, 95\% confidence interval $(\mathrm{CI})$ and the $P$-value using binary logistic regression.

Explorative significance was defined by $P<0.05$. Analyses were performed using the statistics software SPSS $\odot$, version 27 (International Business Machines Corporation (IBM), Armonk, NY).

\section{Results}

Data of $199 \mathrm{CDH}$ patients consisting of 85 female and 114 male patients born between 2001 and 2019 were compared with 597 healthy control infants (289 females and 305 males) born in 2011. Demographics of CDH and controls are shown in Table 1. The male-to-female ratio is hence 1.341 compared to 1.055 in the normal population, which corresponds to an odds ratio (OR) of 1.271 (95\%CI: $0.919,1.757)$ for male gender $(P=0.163) .42$ cases were treated at the University Hospital of Bonn and 157 of $\mathrm{CDH}$ cases were treated at the University Hospital of Mannheim. The majority of CDH-patients was born with a left-sided $\mathrm{CDH}$ (82.9\%), 14.6\% had a right-sided $\mathrm{CDH}$ and one patient presented with bilateral $\mathrm{CDH}$. 66 cases (33.2\%) required ECMO-assistance. $76.4 \%$ of the $\mathrm{CDH}$ patients presented with isolated $\mathrm{CDH}$ defects and $21.6 \%$ were so-called "complex $\mathrm{CDH}$-cases" with additional anomalies. Most of these associated defects were related to the cardiovascular system (62.8\%) followed by malformations of the respiratory, genitourinary, central nervous or gastrointestinal system (Table 2). Both gestational age and birth weight of $\mathrm{CDH}$ cases were significantly lower compared with controls $(P<0.0001)$. There was no statistically significant difference between both groups
Table 2 Further Classification of CDH Patients

\begin{tabular}{ll}
\hline & CDH patients $(\boldsymbol{n}=\mathbf{1 9 9})$ \\
\hline $\begin{array}{ll}\text { Localisation }^{\text {a }} \\
\text { Left }\end{array}$ & $165(82.9 \%)$ \\
Right & $29(14.6 \%)$ \\
bilateral & $1(0.5 \%)$ \\
ECMO required ${ }^{\mathrm{a}}$ & \\
No & $129(64.8 \%)$ \\
Yes & $66(33.2 \%)$ \\
Associated malformations & \\
None & \\
Yes & $152(76.4 \%)$ \\
Cardiovascular & $43(21.6 \%)$ \\
Genitourinary & $34(79.1 \%)$ \\
Centralnervous & $3(7 \%)$ \\
Gastrointestinal & $2(4.6 \%)$ \\
Other & $1(2.3 \%)$ \\
\hline
\end{tabular}

${ }^{\mathrm{a}}$ Data was missing in 4 cases

according to the parent's age at the time of child's birth $(P=0.147$ for maternal age and $P=0.502$ for paternal age). Parent's baseline characteristics according to both groups are shown in Table 3. Altogether we analyzed more than 25 different variables as potential risk factors. The impact of known risk factors for the development of $\mathrm{CDH}$ are summarized in Table 4 (univariate analyses) and Table 5 (multivariate analysis).

Maternal exposure to tobacco, alcohol, coffee, sweeteners and hairspray

We could not find statistical significance for both maternal and paternal periconceptional smoking. The univariate

Table 1 Characteristics of CDH Patients and Control Group

\begin{tabular}{|c|c|c|c|}
\hline & CDH patients $(n=199)$ & Control group $(n=597)$ & $P$ value \\
\hline Gender & & & $0.146^{c}$ \\
\hline Male & $114(57.3 \%)$ & $305(51.1 \%)$ & \\
\hline Female & 85 (42.7\%) & $289(48.4 \%)^{\mathrm{a}}$ & \\
\hline Gestational age, & 37 & 39 & $<0.0001^{d}$ \\
\hline Median (range) & $(32-41)$ & $(21-45)^{\mathrm{b}}$ & \\
\hline Birth weight, & $3020 \mathrm{~g}$ & $3350 \mathrm{~g}$ & $<0.0001^{d}$ \\
\hline Median (range) & $(1600-4600)$ & $(1400-6500)$ & \\
\hline Twins & $7(3.5 \%)$ & $11(1.8 \%)$ & $0.169^{c}$ \\
\hline Monozygotic & $2(28.6 \%)$ & $3(27.3 \%)$ & \\
\hline Dizygotic & $3(42.9 \%)$ & $8(72.7 \%)$ & \\
\hline Unknown & 2 (28.6\%) & & \\
\hline
\end{tabular}

Data was missing in 3 cases.

${ }^{\mathrm{b}}$ Data was missing in 18 cases.

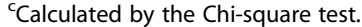

${ }^{\mathrm{d}}$ Calculated by the Mann-Whitney U-test 
Table 3 Parent's Baseline Characteristics according to CDH Patients and Control Group

\begin{tabular}{llll}
\hline & CDH patients $(\boldsymbol{n}=\mathbf{1 9 9})$ & control group $(\boldsymbol{n}=\mathbf{5 9 7})$ & $\boldsymbol{P}_{\text {value }}^{\mathrm{c}}$ \\
\hline Maternal age, median (range) & $32(19-44)$ & $31(17-60)$ & 0.147 \\
Paternal age, median (range) & $34(20-56)$ & $34(19-72)^{\mathrm{a}}$ & 0.502 \\
Number of pregnancies, median (range) & $2(1-12)$ & $2(1-8)^{\mathrm{b}}$ & 0.217 \\
Maternal BMl before pregnancy, median (range) & $23.2(16.8-39.9)^{\mathrm{a}}$ & $22.7(16.4-56.1)^{\mathrm{b}}$ & 0.526 \\
\hline
\end{tabular}

Abbreviation: $B M l$ body mass index $\left(\mathrm{kg} / \mathrm{m}^{2}\right)$

${ }^{a}$ Data was missing in 6 cases

${ }^{b}$ Data was missing in 17 cases

${ }^{c}$ Calculated by Mann-Whitney U-test

analyses demonstrated statistical significance for maternal periconceptional alcohol intake $(P=0.025)$, which retained its significance using binary logistic regression $(\mathrm{OR}=$ 1.639; 95\% CI: $1.101,2.440, P=0.015)$. There was no connection between the development of $\mathrm{CDH}$ and periconceptional maternal consumption of coffee or sweeteners. A significantly increased risk for $\mathrm{CDH}$ was observed with maternal periconceptional use of hairspray $(\mathrm{OR}=2.072$; 95\% CI: 1.330, 3.229; $P=0.001$ ).

\section{Maternal BMI and chronic diseases}

Neither maternal underweight, nor maternal overweight or even obesity seemed to have an impact on the risk of $\mathrm{CDH}$ development, $P$-values for maternal BMI are shown in Table 4. Maternal hypothyroidism as chronic disease showed borderline significant association with CDH development $(P=0.051)$.

\section{Maternal periconceptional folic acid supplementation, previous miscarriages, and hormone substitution}

There was no association between the development of $\mathrm{CDH}$ and periconceptional maternal folic acid intake $(P=0.165)$. Previous miscarriages and pregnancy as a result of hormone treatment showed association $(P=$ 0.040 and 0.016 ) in univariate analyses but was not associated anymore when analyzed in a binary logistic regression model.

\section{Maternal periconceptional contact to animals}

Maternal periconceptional contact to animals presented as significant $(P=0.03)$ in univariate analyses with an even lower $P$-value for maternal periconceptional contact to cats $(P=0.014)$, but both variables did not remain significant in multivariate analyses.

\section{Discussion}

Here, in a case-control study we investigated potential environmental risk factors in $199 \mathrm{CDH}$ patients compared to 597 healthy control newborns. Our analyses did not find association between parental periconceptional smoking and $\mathrm{CDH}$. However, we observed significant association for maternal periconceptional alcohol intake. Accordingly, previous studies by Felix et al. in 2008 and
McAteer et al. in 2014 described association between the occurrence of $\mathrm{CDH}$ and maternal periconceptional alcohol intake $[11,16]$. In general, $\mathrm{CDH}$ is not part of the foetal alcohol related anomaly spectrum [17]. Nevertheless, previous studies report an association of maternal alcohol consumption and the expression of birth defects [18]. Yet, no pathophysiological concept exists that could causally link periconceptional or pregnancy related maternal alcohol consumption and the expression of structural birth defects. Likely, the observational association of maternal alcohol consumption with structural birth defects is more of an indirect association, warranting future studies, observational or experimental, to investigate this. The here described association between maternal periconceptional use of hairspray, the development of $\mathrm{CDH}$, and the fact that hairsprays have already been discussed to possibly bear an impact on pregnancy and embryogenesis warrants further studies [19]. Especially, since a recent study by Karzi et al. in 2019 showed that the frequent use of hairspray and sunscreens is correlated with higher levels of parabens in hair of the pregnant women [20]. Recently, several experimental studies have investigated the embryonic toxicity of parabens using zebrafish larvae providing several lines of evidence, for the detrimental effects of parabens on zebrafish early-life stages with attention to its developmental toxicity [21, 22]. Observed features among zebrafish larvae where pericardial edema, yolk edema, blood stasis, reduction in blood circulation, reduced heartbeat and notochord curvature [23]. While parabens are commonly found in personal care products such as hair spray, it is unclear, whether the maternal use during the periconceptional period might exert toxic effects on human embryonic development. Hence, the current observation should warrant measurements of parabens in women using on a regular level hair spray or paraben containing care products and correlate the measured quantities in women to the toxic quantities used in the above mentioned zebrafish studies.

While previous studies suggested an association of periconceptional maternal overweight and $\mathrm{CDH}[24,25]$ our study could not replicate this association $(P=0.526)$. The studies of García et al. published in 2016 [9] and 
Table 4 Univariate Associations between Maternal or Paternal Factors and CDH

\begin{tabular}{|c|c|c|c|}
\hline & Control group $(n=597)$ & CDH patients $(n=199)$ & $P$ value $^{a}$ \\
\hline \multicolumn{4}{|c|}{ Maternal periconceptional smoking ${ }^{b}$} \\
\hline No smoking & $456(76 \%)$ & $161(81 \%)$ & \\
\hline Any smoking & $133(22 \%)$ & $37(19 \%)$ & 0.265 \\
\hline 1-5 cigarettes/day & $38(6.5 \%)$ & $14(7 \%)$ & 0.896 \\
\hline $6-10$ cigarettes/day & $36(5.9 \%)$ & $10(5 \%)$ & 0.515 \\
\hline$>10$ cigarettes/day & $59(9.9 \%)$ & $13(6.5 \%)$ & 0.153 \\
\hline \multicolumn{4}{|c|}{ Paternal periconceptional smoking ${ }^{c}$} \\
\hline No smoking & 385 (64\%) & $138(69 \%)$ & \\
\hline Any smoking & $181(31 \%)$ & $54(29 \%)$ & 0.211 \\
\hline 1-5 cigarettes/day & $5(0.8 \%)$ & $9(4.5 \%)$ & 0.318 \\
\hline 6-10 cigarettes/day & $30(5 \%)$ & $14(7 \%)$ & 0.435 \\
\hline$>10$ cigarettes/day & $146(24.5 \%)$ & $31(15.5 \%)$ & 0.017 \\
\hline \multicolumn{4}{|c|}{ Maternal periconceptional alcohol intake ${ }^{d}$} \\
\hline No & $165(28 \%)$ & $55(28 \%)$ & \\
\hline Yes & $266(45 \%)$ & $135(68 \%)$ & 0.025 \\
\hline \multicolumn{4}{|c|}{ Paternal periconceptional alcohol intake } \\
\hline No & $81(14 \%)$ & $30(15 \%)$ & \\
\hline Yes & $340(57 \%)$ & $156(78 \%)$ & 0.361 \\
\hline \multicolumn{4}{|c|}{ Maternal periconceptional coffee intake ${ }^{f}$} \\
\hline No & $99(17 \%)$ & $40(20 \%)$ & \\
\hline Yes & $443(74 \%)$ & $155(78 \%)$ & 0.492 \\
\hline$\geq 30$ units/month & $309(52 \%)$ & $128(64 \%)$ & 0.908 \\
\hline \multicolumn{4}{|c|}{ Maternal periconceptional sweetener intake ${ }^{g}$} \\
\hline No & $202(34 \%)$ & $101(51 \%)$ & \\
\hline Yes & $163(27 \%)$ & $89(45 \%)$ & 0.624 \\
\hline$\geq 30$ units/month & $50(8 \%)$ & $22(11 \%)$ & 0.481 \\
\hline \multicolumn{4}{|c|}{ Maternal periconceptional use of hairspray ${ }^{\mathrm{h}}$} \\
\hline No & $470(79 \%)$ & $146(73 \%)$ & \\
\hline Yes & $95(16 \%)$ & $49(25 \%)$ & 0.011 \\
\hline \multicolumn{4}{|c|}{ Maternal periconceptional BMP } \\
\hline$<18.5 \mathrm{~kg} / \mathrm{m}^{2}$ & $23(4 \%)$ & $5(2.5 \%)$ & 0.376 \\
\hline $18.5-24.9 \mathrm{~kg} / \mathrm{m}^{2}$ & $390(65 \%)$ & $132(66 \%)$ & 0.764 \\
\hline $25-29.9 \mathrm{~kg} / \mathrm{m}^{2}$ & $87(15 \%)$ & $36(18 \%)$ & 0.229 \\
\hline$\geq 30 \mathrm{~kg} / \mathrm{m}^{2}$ & $74(12 \%)$ & $18(9 \%)$ & 0.202 \\
\hline \multicolumn{4}{|l|}{ Maternal hypothyreosis } \\
\hline Yes & $20(3.3 \%)$ & $13(6.5 \%)$ & 0.051 \\
\hline \multicolumn{4}{|c|}{ Maternal periconceptional folic acid intake } \\
\hline No & 385 (64\%) & $115(58 \%)$ & \\
\hline Yes & $212(36 \%)$ & $84(42 \%)$ & 0.165 \\
\hline \multicolumn{4}{|l|}{ Previous miscarriages ${ }^{k}$} \\
\hline No & $438(73 \%)$ & $141(71 \%)$ & \\
\hline Yes & 111 (19\%) & 53 (27\%) & 0.04 \\
\hline
\end{tabular}


Table 4 Univariate Associations between Maternal or Paternal Factors and CDH (Continued)

\begin{tabular}{|c|c|c|c|}
\hline & Control group $(n=597)$ & CDH patients $(n=199)$ & $P$ value $^{\mathrm{a}}$ \\
\hline \multicolumn{4}{|c|}{ Pregnancy after infertility treatment ${ }^{\prime}$} \\
\hline No & $544(91 \%)$ & 177 (89\%) & \\
\hline Yes & $35(6 \%)$ & $20(10 \%)$ & 0.052 \\
\hline Hormone treatment & $11(2 \%)$ & $10(5 \%)$ & 0.016 \\
\hline \multicolumn{4}{|c|}{ Maternal periconceptional contact to animals ${ }^{m}$} \\
\hline No & $494(83 \%)$ & $160(80 \%)$ & \\
\hline Yes & $73(12 \%)$ & $38(19 \%)$ & 0.03 \\
\hline Especially cats & $40(7 \%)$ & $25(13 \%)$ & 0.014 \\
\hline
\end{tabular}

${ }^{a}$ Calculated by the Chi-square test

${ }^{b}$ Data was missing in 9 cases in the control group and 1 case in the $\mathrm{CDH}$ group

'Data was missing in 31 cases in the control group and 7 cases in the $\mathrm{CDH}$ group

${ }^{\mathrm{d} D a t a}$ was missing in 166 cases in the control group and 9 cases in the $\mathrm{CDH}$ group

e Data was missing in 176 cases in the control group and 13 cases in the $\mathrm{CDH}$ group

fData was missing in 57 cases in the control group and 4 cases in the CDH group

${ }^{9}$ Data was missing in 232 cases in the control group and 9 cases in the $\mathrm{CDH}$ group

hData was missing in 32 cases in the control group and 4 cases in the $\mathrm{CDH}$ group

jData was missing in 23 cases in the control group and 8 cases in the $\mathrm{CDH}$ group

${ }^{\mathrm{k}}$ Data was missing in 48 cases in the control group and 5 cases in the $\mathrm{CDH}$ group

'Data was missing in 18 cases in the control group and 2 cases in the CDH group

${ }^{m}$ Data was missing in 30 cases in the control group and 1 case in the $\mathrm{CDH}$ group

Paoletti et al. published in 2020 [10] revealed a significant increased risk of bearing a child with $\mathrm{CDH}$ for mothers with an age $\geq 35$ years $(P<0.001$ and $P=$ $0.0004)$. While our study did not replicate this association, median maternal age of both, case and control mothers in our study, was below 35 years of age. In 2014, McAteer et al. [11] described an association between maternal pregestational diabetes and $\mathrm{CDH}(P=$ 0.003). Our study could not replicate this finding $(P=$ 0.827). Furthermore, we did not observe the previously described association between periconceptional maternal hypertension and CDH by Mesas Burgos et al. in 2019 [12]. In fact, we did not find any association between maternal chronic diseases of the cardiovascular or respiratory spectrum and $\mathrm{CDH}$ in their offspring. However, our study is suggestive $(P=0.051)$ for an association between maternal periconceptional hypothyreosis and $\mathrm{CDH}$ which should warrant further studies in the future.

Our study did not reveal any potential associations between maternal periconceptional intake of medical drugs and $\mathrm{CDH}$. Here, Crider et al. had previously observed an association between periconceptional maternal intake of sulfonamides and $\mathrm{CDH}$ [26]. Furthermore, our results do not support maternal periconceptional folic acid supplementation to be

Table 5 Statistically Significant Risk Factors for $\mathrm{CDH}$ in Multivariate Analyses

\begin{tabular}{llll}
\hline & OR & $\mathbf{9 5 \%} \mathbf{C l}$ & $\boldsymbol{P}$ value \\
\hline Maternal periconceptional alcohol intake & 1.639 & $1.101-2.440$ & 0.015 \\
Maternal periconceptional use of hairspray & 2.072 & $1.330-3.229$ & 0.001
\end{tabular}

Abbreviations: OR Odds Ratio, Cl Confidence Interval protective in the prevention of $\mathrm{CDH}$. However, prevention of $\mathrm{CDH}$ has not been an indication for maternal periconceptional folic acid supplementation.

Regarding periconceptional maternal vitamin supplementation, the respective questionnaire items were barely answered except for folic acid intake. This is most likely due to the fact, that in Germany, no monitoring or systematic information exists on what and how many vitamins should be supplemented during pregnancy, except for folic acid. Nevertheless, previous reports by Beurskens et al. in 2013 [27] describe an association between 'dietary vitamin A intake during pregnancy below the recommended daily intake $(800 \mu \mathrm{g}$ per day $)$ in normal-weight mothers' and the risk of bearing a child with $\mathrm{CDH}(P=0.01)$. Recently Carmichael et al. described low maternal qualitative diets and lack of riboflavin to be associated with $\mathrm{CDH}$ formation in the offspring [13]. Moreover, Turkmen et al. described lower maternal vitamin D $(P=0.019)$ and calcium levels $(P<$ 0.001 ) to be associated with 'pregnancies complicated by $\mathrm{CDH}^{\prime}$ and hypothesized that hypovitaminosis $\mathrm{D}$ may 'play a vital role in the pathogenesis of $\mathrm{CDH}^{\prime}$ [28]. The exact mechanisms of different hypo- or hypervitamonsis and the expression of birth defects are vastly unknown. Yet, the observations made for transcription factor GATA-4, encoded by the GATA4 gene (MIM \#600576) and its function in a vitamin A-deficient embryonic environment could be of model character. GATA4 belongs to the few genes identified to play a role in human $\mathrm{CDH}$ formation [29]. On the other hand, Feng et al. were able to show in an experimental mouse study, that the mouse embryos of vitamin A-deficient mothers, presented with a high incidence of cardiac defects [30]. Interestingly, 
they also found high methylation status in the CpG loci of GATA4 gene with a low expression of GATA-4 mRNA from vitamin A-deficient group embryos. Hence, embryonic transcriptome maps of the developing diaphragm in vertebrates could yield further genetic drivers, that may play a role in (human) diaphragm development allowing for the identification of genetic drivers, that require certain vitamins or track elements. Here, hypomorphic alleles, possibly discovered by genome-wide association studies and a deficient intrauterine environment might lead to $\mathrm{CDH}$ or other common birth defects.

To the best of our knowledge, the present study is the first German study that assessed the potential association between $\mathrm{CDH}$ and various parental environmental risk factors. Here, we were able to recruit a large sample of $\mathrm{CDH}$ families and respective healthy controls newborns in a match of 1:3 (cases:controls) to yield maximal statistical power and to facilitate the detection of associations between potential risk factors and $\mathrm{CDH}$.

Our study is limited by a potential recall bias among $\mathrm{CDH}$ case mothers or fathers due to the retrospective collection of data, which in some cases was carried out up to 17 years after the child's birth whereas the control group received the questionnaire almost immediately after delivery. Furthermore, we cannot exclude, a potential bias in both groups, cases and controls, especially among case parents in that parents with an unhealthy lifestyle habit might not have been willing to participate due to guilt feelings. Nevertheless, our results suggest an increased direct or indirect risk for $\mathrm{CDH}$ formation to be associated with maternal periconceptional alcohol consumption regardless of the beverage chosen or the frequency of consumption. Furthermore, we observed an association between maternal periconceptional use of hairspray, which might point to an embryonic impact of parabens on embryonic development.

\section{Abbreviations}

$\mathrm{CDH}$ : Congenital diaphragmatic hernia; ICSI: Intracytoplasmic sperm injection; IVF: In vitro fertilization

\section{Authors' contributions}

The study was designed by FS and HR. All authors contributed to acquisition of data. Statistical analysis and interpretation of the data were carried out by FS and EJ. Drafting of the article was done by FS, EJ and HR. All authors revised the article. All authors read and approved the final manuscript.

\section{Funding}

No funds, grants, or other support was received. Open Access funding enabled and organized by Projekt DEAL.

\section{Availability of data and materials}

"The datasets generated and analysed during the current study are not publicly available due to privacy of the participating families and sensitivity issues but are available from the corresponding author on reasonable request.

\section{Declarations}

Ethics approval and consent to participate

The respective ethics committees of the University Hospital of Bonn and Mannheim approved our study. The involved human data was in accordance with the guidelines of the Declaration of Helsinki. Prior to inclusion, written informed consent was obtained from all patients respectively their parents.

\section{Consent for publication}

Written informed consent to publish was obtained from all patients respectively their parents.

\section{Competing interests}

The authors declare that they have no competing interests.

\section{Author details}

'Department of Neonatology and Pediatric Intensive Care, Children's Hospital, University of Bonn, Bonn, Germany. ${ }^{2}$ Department of Hematology, Oncology and Clinical Immunology, University Hospital Düsseldorf, Düsseldorf, Germany. ${ }^{3}$ Department of Child and Adolescent Psychiatry, University Medical Center of the Johannes Gutenberg University Mainz, Mainz, Germany. "Faculty of Health, School of Medicine, University of Witten/ Herdecke, Witten, Germany. ${ }^{5}$ Department of Surgery, University Hospital Bonn, Bonn, Germany. ${ }^{6}$ Department of Neonatology, University Children's Hospital Mannheim, University of Heidelberg, Mannheim, Germany.

${ }^{7}$ Department of Pediatric Surgery, University Hospital Bonn, Bonn, Germany. ${ }^{8}$ Department of Pediatric Surgery, University Hospital Mannheim, Mannheim, Germany. ${ }^{9}$ Institute of Human Genetics, University Hospital Bonn, Bonn, Germany.

Received: 4 March 2021 Accepted: 21 May 2021

Published online: 14 June 2021

\section{References}

1. McGivern MR, Best KE, Rankin J, Wellesley D, Greenlees R, Addor MC, et al. Epidemiology of congenital diaphragmatic hernia in Europe: a registerbased study. Arch Dis Child Fetal Neonatal Ed. 2015;100(2):F137-44. https:// doi.org/10.1136/archdischild-2014-306174 Epub 2014 Nov 19.

2. van den Hout L, Schaible T, Cohen-Overbeek TE, Hop W, Siemer J, van de Ven K, et al. Actual outcome in infants with congenital diaphragmatic hernia. The role of a standardized postnatal treatment protocol. Fetal Diagn Ther. 2011;29(1):55-63. https://doi.org/10.1159/000322694.

3. Moore KL, Persaud TVN, Torchia MG (Hg.) (2008): The developing human: clinically oriented embryology. 8th edn. Philadelphia: Saunders.

4. Veenma DCM, de Klein A, Tibboel D. Developmental and genetic aspects of congenital diaphragmatic hernia. Pediatr Pulmonol. 2012;47(6):534-45. https://doi.org/10.1002/ppul.22553.

5. Clugston RD, Zhang W, Alvarez S, Lera, Angel R. de; Greer, John J. Understanding abnormal retinoid signaling as a causative mechanism in congenital diaphragmatic hernia. Am J Respir Cell Mol Biol. 2010;42(3):27685. https://doi.org/10.1165/rcmb.2009-00760C.

6. Pober BR. Genetic aspects of human congenital diaphragmatic hernia. Clin Genet. 2008;74(1):1-15. https://doi.org/10.1111/j.1399-0004.2008.01031.x Epub 2008 May 28.

7. Gregory ME, Cox VA, Goldstein RB, Gibbs DL, Harrison MR, Golabi M. Congenital diaphragmatic defects and associated syndromes, malformations, and chromosome anomalies: A retrospective study of 60 patients and literature review. Am J Med Genet. 1998;(79):S. 215-25.

8. Blomberg MI, Källén B. Maternal obesity and morbid obesity: the risk for birth defects in the offspring. Birth Defects Res A Clin Mol Teratol. 2010; 88(1):35-40. https://doi.org/10.1002/bdra.20620.

9. García AM, Machicado S, Gracia G, Zarante IM. Risk factors for congenital diaphragmatic hernia in the Bogota birth defects surveillance and follow-up program, Colombia. Pediatr Surg Int. 2016;32(3):227-34. https://doi.org/10.1 007/s00383-015-3832-7 Epub 2015 Nov 16.

10. Paoletti M, Raffler G, Gaffi MS, Antounians L, Lauriti G, Zani A. Prevalence and risk factors for congenital diaphragmatic hernia: A global view. J Pediatr Surg. 2020;55(11):2297-307. https://doi.org/10.1016/j.jpedsurg.2020.06.022 Epub 2020 Jun 20

11. McAteer JP, Hecht A, De Roos AJ, Goldin AB. Maternal medical and behavioral risk factors for congenital diaphragmatic hernia. J Pediatr Surg. 
2014;49(1):34-8; discussion 38. https://doi.org/10.1016/j.jpedsurg.2013.09.025 Epub 2013 Oct 5.

12. Mesas Burgos $C$, Ehrén $H$, Conner P, Frenckner B. Maternal risk factors and perinatal characteristics in congenital diaphragmatic hernia: a Nationwide population-based study. Fetal Diagn Ther. 2019;46(6):385-91. https://doi. org/10.1159/000497619.

13. Carmichael SL, Ma C, Witte JS, Yang W, Rasmussen SA, Brunelli L, et al. Feldkamp ML; National Birth Defects Prevention Study. Congenital diaphragmatic hernia and maternal dietary nutrient pathways and diet quality. Birth Defects Res. 2020;112(18):1475-83. https://doi.org/10.1002/ bdr2.1770.

14. Chatterjee D, Ing RJ, Gien J. Update on congenital diaphragmatic hernia. Anesth Analg. 2020;131(3):808-21. https://doi.org/10.1213/ANE. 0000000000004324.

15. Zwink N, Rissmann A, Pötzsch S, Reutter H, Jenetzky E. Parental risk factors of anorectal malformations. Analysis with a regional population-based control group. Birth Defects Res A Clin Mol Teratol. 2016;106(2):133-41. https://doi.org/10.1002/bdra.23469.

16. Felix JF, van Dooren MF, Klaassens M, Hop WC, Torfs CP, Tibboel D. Environmental factors in the etiology of esophageal atresia and congenital diaphragmatic hernia: results of a case-control study. Birth Defects Res A Clin Mol Teratol. 2008;82(2):98-105. https://doi.org/10.1002/bdra.20423.

17. Colom J, Segura-García L, Bastons-Compta A, Astals M, Andreu-Fernandez V, Barcons N, et al. Prevalence of Fetal Alcohol Spectrum Disorders (FASD) among Children Adopted from Eastern European Countries: Russia and Ukraine. Int J Environ Res Public Health. 2021;18(4):1388. https://doi.org/1 0.3390/ijerph18041388 PMID: 33546212; PMCID: PMC7913360.

18. Oh SS, Park S, You YA, Jee Y, Ansari A, Kim SM, et al. Prenatal Exposure to Alcohol, Tobacco, and Coffee: Associated Congenital Complications and Adverse Birth Outcomes. Int J Environ Res Public Health. 2021;18(6):3140. https://doi.org/10.3390/ijerph18063140 PMID: 33803679; PMCID: PMC8003057.

19. Haraux E, Braun K, Buisson P, Stéphan-Blanchard E, Devauchelle C, Ricard J, et al. Maternal exposure to domestic hair cosmetics and occupational endocrine disruptors is associated with a higher risk of hypospadias in the offspring. Int J Environ Res Public Health. 2016;14(1):27. https://doi.org/10.33 90/ijerph14010027.

20. Karzi V, Tzatzarakis M, Katsikantami I, Stavroulaki A, Alegakis A, Vakonaki E, et al. Investigating exposure to endocrine disruptors via hair analysis of pregnant women. Environ Res. 2019;178:108692. https://doi.org/10.1016/j. envres.2019.108692.

21. de Carvalho Penha LC, Coimbra Rola R, da Silva Junior FM. de Martinez Gaspar martins C. toxicity and sublethal effects of methylparaben on zebrafish (Danio rerio) larvae and adults. Environ Sci Pollut Res Int. 2021;18. https://doi.org/10.1007/s11356-021-12800-5 Epub ahead of print. PMID: 33866511 .

22. Merola C, Lucon-Xiccato T, Bertolucci C, Perugini M. Behavioural effects of early-life exposure to parabens in zebrafish larvae. J Appl Toxicol. 2021. https://doi.org/10.1002/jat.4171 Epub ahead of print. PMID: 33826164.

23. Merola C, Perugini M, Conte A, Angelozzi G, Bozzelli M, Amorena M Embryotoxicity of methylparaben to zebrafish (Danio rerio) early-life stages. Comp Biochem Physiol C Toxicol Pharmacol. 2020;236:108792. https://doi. org/10.1016/j.cbpc.2020.108792 Epub 2020 May 16. PMID: 32428600.

24. Waller DK, Shaw GM, Rasmussen SA, Hobbs CA, Canfield MA, Siega-Riz AM, et al. Correa a; National Birth Defects Prevention Study. Prepregnancy obesity as a risk factor for structural birth defects. Arch Pediatr Adolesc Med. 2007;161(8):745-50. https://doi.org/10.1001/archpedi.161.8.745

25. Block SR, Watkins SM, Salemi JL, Rutkowski R, Tanner JP, Correia JA, et al. Maternal pre-pregnancy body mass index and risk of selected birth defects: evidence of a dose-response relationship. Paediatr Perinat Epidemiol. 2013; 27(6):521-31. https://doi.org/10.1111/ppe.12084

26. Crider KS, Cleves MA, Reefhuis J, Berry RJ, Hobbs CA, Hu DJ. Antibacterial medication use during pregnancy and risk of birth defects: National Birth Defects Prevention Study. Arch Pediatr Adolesc Med. 2009;163(11):978-85. https://doi.org/10.1001/archpediatrics.2009.188.

27. Beurskens LW, Schrijver LH, Tibboel D, Wildhagen MF, Knapen MF, Lindemans J, et al. Dietary vitamin A intake below the recommended daily intake during pregnancy and the risk of congenital diaphragmatic hernia in the offspring. Birth Defects Res A Clin Mol Teratol. 2013;97(1):60-6. https:// doi.org/10.1002/bdra.23093 Epub 2013 Jan 2.
28. Turkmen GG, Timur H, Tokmak A, Yilmaz Z, Kirbas A, Daglar K, et al Levels of serum vitamin $D$ and calcium in pregnancies complicated with fetal congenital diaphragmatic hernia and normal pregnancies. J Matern Fetal Neonatal Med. 2017:30(8):990-4. https://doi.org/10.1080/14 767058.2016.1196662.

29. Kardon G, Ackerman KG, McCulley DJ, Shen Y, Wynn J, Shang L, et al. Congenital diaphragmatic hernias: from genes to mechanisms to therapies. Dis Model Mech. 2017;10(8):955-70. https://doi.org/10.1242/dmm.028365 PMID: 28768736; PMCID: PMC5560060.

30. Feng $Y$, Zhao LZ, Hong L, Shan C, Shi W, Cai W. Alteration in methylation pattern of GATA-4 promoter region in vitamin A-deficient offspring's heart. J Nutr Biochem. 2013;24(7):1373-80. https://doi.org/10.1 016/j.jnutbio.2012.11.005 Epub 2013 Jan 17. PMID: 23333085.

\section{Publisher's Note}

Springer Nature remains neutral with regard to jurisdictional claims in published maps and institutional affiliations.

Ready to submit your research? Choose BMC and benefit from:

- fast, convenient online submission

- thorough peer review by experienced researchers in your field

- rapid publication on acceptance

- support for research data, including large and complex data types

- gold Open Access which fosters wider collaboration and increased citations

- maximum visibility for your research: over $100 \mathrm{M}$ website views per year

At $\mathrm{BMC}$, research is always in progress.

Learn more biomedcentral.com/submissions 